\title{
Time consistency and bureaucratic budget competition
}

\author{
Sebastian G. Kessing* and Kai A. Konrad ${ }^{\dagger}$
}

November 4, 2004

\begin{abstract}
We provide a new explanation for higher labor intensity in the public sector based on the theory of bureaucracy. Tenure in the public sector results in strategic over-employment if government divisions compete for budgets intertemporally. Bureaucrats who are interested in maximising their divisions' output employ excess labor, since this induces the sponsor to provide complementary inputs in the future. The resulting inefficiency in the expenditure structure is more severe in periods in which large future budget increases are unlikely and reveals a possible efficiency cost of stagnation.

Keywords: bureaucratic competition, time consistency, labor intensity, public sector

JEL classification numbers: H11, H61, H83
\end{abstract}

${ }^{*}$ Free University of Berlin and WZB

${ }^{\dagger}$ WZB and Free University of Berlin. Correspondence to: Kai A. Konrad, WZB, Reichpietschufer 50, D-10777 Berlin, Germany. Phone: +49-30-25491-401, fax: -49-30-25491400, e-mail: kkonrad@wz-berlin.de. 


\section{Introduction}

The public sector is more labor intensive than the private sector. For instance, Dewenter and Malatesta (2001), using an international cross section data set of Fortune 500 companies, found that public enterprises have significantly greater employees-to-sales ratios. Furthermore, they also conducted time series analysis on the change of labor intensity in the course of privatization, showing that firms have lower labor intensity after privatization. Similarly, country studies by La Porta and Lopez-de-Silanes (1999) and Omran (2004) also found that privatization in Mexico and Egypt, respectively, reduced employment, while at the same time maintaining or expanding output. ${ }^{1}$

The existing explanations for increased labor intensity in the public sector broadly fall into two categories. One prominent theory is the rent-seeking and political patronage view. It maintains that overmanning in the public sector is the result of rent-seeking activities and provides a way for politicians to channel rents to groups that serve as their power base (see Gelb, Knight and Sabot (1991)). Alesina, Baquir and Easterly (2000) show that, under particular informational asymmetries, politicians can have an incentive to prefer the relatively inefficient instrument of public employment over direct redistribution towards a particular group. ${ }^{2}$ Empirically, Lopez-de-Silanes, Shleifer and Vishny (1997) find evidence that politicians create or use wellpaid jobs in public enterprises to strengthen their political support.

The second kind of explanation has tried to explain increased labor intensity within the framework of fully benevolent policy makers. Poutvaara and Wagener (2004), for example, make a second best argument for increased

\footnotetext{
${ }^{1}$ For surveys and further evidence, see Megginson and Netter (2001), Gupta, Schiller, Ma and Tiongson (2001), and Haltiwanger and Singh (1999).

${ }^{2}$ See also Boycko, Shleifer and Vishny (1996) who argue that the political patronage view is compatible with the reductions in employment after privatisation. The reason is that the transfer of the control rights over the employment decision changes the nature of the costs of such over-employment. With the resulting increase in costs, subsidies to the privatized firms for generating additional employment are not such a desirable option as reduced profits were before.
} 
labor intensity. Since public sector decision makers realise that the proceeds from labor taxation will net out in their budget, they base their decision to hire on the net cost of labor, which, in a world with elastic labor supply, increases efficiency. Similarly, Forni and Giordano (2003) show that if governments care about unemployment, for political or benevolent reasons, the interaction of particular wage setting institutions in the private and public sectors can also give rise to relatively more labor intensive production in the public sector. Finally, Rodrik (2000) argues that public sector employment provides partial insurance against otherwise undiversifiable risk and shows that public sector employment is positively correlated with countries' openess and their exposure to external shocks. Gordon (2003) develops the efficiency argument more generally and gives further instances where increased public employment may be efficiency enhancing.

We give a new alternative explanation for the higher labor intensity in the public sector that neither relies on benevolent policy makers' intentions to correct some existing market failure nor depends on particular motives of self-interested politicians. Instead, our explanation is related to the theory of bureaucracy. We start with the observation that civil servants enjoy particular job tenure, and use this as the decisive difference between private and public enterprises. Combined with decentralized decision making and centralized, time consistent budget allocation, higher job tenure will lead to higher labor intensity in the public sector. Comparing our explanation with the existing ones, it is evident that our approach and these explanations are not mutually exclusive but should be regarded as complementary.

To illustrate our main idea, consider the effect of present hiring decisions in a university on budget allocation decisions in the future. The president of the university or its governing body annually allocates the budget among the departments or faculties. Suppose for the sake of the argument that a department could decide completely freely about how to use the money of year $t$ on permanent faculty and on other research and teaching inputs such as office space, laboratory equipment, library budget etc. The department may find that it is in its interest to use most of the budget to hire permanent faculty, even if this may imply a current shortage in these other research 
inputs: once new faculty is hired irreversibly, the university president will find it in his interest to endow the professors in this department with offices, library and other, complementary inputs for the production of research and teaching output, instead of having them share offices computers, equipment, etc. Hiring today may, hence, increase the budget of the department tomorrow. If all divisions try to use this mechanism, for a given overall budget they will end up with more faculty per unit of departmental or university budget (higher labor intensity) than is optimal. ${ }^{3}$

Note that the same story also applies for a public university as a whole with respect to its public sponsor, and may be even more relevant here, because the university as a whole has more discretion about the hiring decisions than a single department, and this may explain why the university leaders may be more lenient than is optimal with respect to departmental demands for additional permanent faculty.

The mechanism crucially relies on the assumption about tenure. If the chief bureaucrat of a division can simply adjust and reduce the labor force to its optimal level in any period for any given budget, hiring decisions today have no commitment value for tomorrow. However, job tenure is typically very strong in the public sector and much lower in the private sector. This explains why these mechanisms are at work only in the public sector, and, hence, the difference in labor intensity.

An important hypothesis that results from our analysis can be tested empirically. According to our theory, the strategic effect will be asymmetric with respect to non-expansionary and expansionary time periods. The strategic incentive to hire permanent labor in order to induce a favorable budget shift in the future is particularly strong in time periods in which the overall governmental budget cannot be expected to expand by much. If, instead, a major expansion of the aggregate government budget is anticipated,

\footnotetext{
${ }^{3}$ Formally, the effectiveness of this mechanism is often deliberately mitigated in bureaucratic units such as university departments by formal procedures which limit a department's discretion for hiring permanent faculty without the consent of the central decision unit. However, this mechanism will still be at work to some extent through influence activities and lobbying.
} 
even a major amount of permanent hiring today does not have much strategic effect. Accordingly, we expect that labor intensity is highest in periods in which expansions of the overall budget for which the bureaucracy divisions compete are not expected for the near future.

Our theory is closely linked to two lines of the literature and can be seen as a contribution to both. First, a considerable amount of work in political economy, and in particular, in the context of voting, discusses the importance of decisions with a lasting impact on future elections, and for the decision making of future government. For instance, Persson and Svensson (1989) discuss the commitment effects of government debt for future governments, and its strategic role. More directly related to our analysis, Glazer (1989) discusses the use of durable projects and how the choice of the durability of a project may affect future election outcomes and future policy decisions. Crain and Oakley (1995) test this theory indirectly, confirming that political institutions that affect the political sustainability of policy choices have an impact on infrastructure spending. The common link between these analyses and this paper is that durability yields commitment, and hence, becomes a strategic instrument.

Second, our analysis in which the chief bureaucrats of several divisions compete for resources from a given overall governmental budget is closely related to the literature on bureaucracy. This literature received a first, important stimulus with Niskanen (1971) and since then has been growing fast. For more of an overall picture of the field, see, e.g., Kraan (1996). ${ }^{4}$ Much of the literature considers the static problem, but some earlier work also addresses multi-period issues, such as Carlsen and Haugen (1994) or Bagnoli and McKee (1991). While we consider a time consistency problem in a two-period framework, they consider infinitely repeated games between the bureaucrat(s) and the sponsor who decides about the bureaucrat's budgets. A central focus of this literature is on how to control the bureaucrat who has an incentive to earn some rent from reduced effort, or 'slack'. We will

\footnotetext{
${ }^{4}$ Laffont and Tirole (1993) were also very influential, using standard tools from contract theory to address a wide scope of regulation issues related to bureaucracy or the public sector.
} 
consider bureaucrats whose production opportunities are perfectly known, so that actual slack, or agency rents from private information can be avoided. Our paper is closely related to Moene (1986) and Chan and Mestelman (1988) who consider the strategic interaction between one bureaucrat and his sponsor. Moene (1986), for instance, considers timing of decision making between a bureau and the sponsor (who grants the budget), where the bureau may try to trigger higher payments by generating a high expenditure bill. One of the central, and, to our knowledge, new aspects we consider is the decomposition of the bureacrat's decision to produce with two inputs, one of which is durable, and to analyse if, how, and when this is used strategically. Also, we focus on the competition between two or more bureaucrats who compete for budget shares. Competition among bureaucrats has also been considered in the literature by Bagnoli and McKee (1991). They argue that such competition can be used as a disciplinary device. We show that, given the discretion of the bureaucrats in early periods, the inefficiency emerges here precisely because of the competition between divisions.

We proceed as follows. In the next section (section 2) we outline the central analytical framework. In section 3 we characterize the efficiency benchmark case in this framework. In section 4 we derive the main results on the role of tenured labor as a strategic instrument in the competition between bureaucrats. Section 5 concludes.

\section{The analytic framework}

Consider a simple two period framework of a government with a bureaucracy that consists of divisions $i=x, y$. The government has an overall budget $B(t)$ for each period $t=0,1$. This budget is fully used by distributing it to the divisions, such that

$$
B(t)=b_{x}(t)+b_{y}(t)
$$

where $b_{i}(t)$ denotes divisions' budgets. Each division is headed by a bureaucrat who freely allocates the bureau's budget between two input factors, one of which is durable, and its quantity is used in period $t$ by division $i$ is 
denoted $l_{i}(t) .{ }^{5}$ For concreteness, and because our analysis aims at explaining the empirically observed high labor intensity, we call the durable factor tenured labor. The other factor is non-durable. Its quantity is denoted $z_{i}(t)$. This factor describes inputs such as paper, pencils, electricity, rented office space, or even durable goods that, however, can be sold at the end of a period.

We consider a partial model in which the governmental sector is only a small share in the whole economy so that the factor input choices in the divisions do not affect equilibrium factor prices and normalize all factor prices to unity. This implies that the budget constraint of the bureaucrat in division $i$ in period $t$ can be written as

$$
b_{i}(t) \geq l_{i}(t)+z_{i}(t) \text { for } t=0,1
$$

and expenditure on $l_{i}$ and $z_{i}$ are chosen by the division's bureaucrat at the beginning of each respective period once the size $b_{i}(t)$ of the period budget is known to the division.

As the civil servants are tenured, employment decisions made in period $t=0$ have a lasting impact on period 1 employment. We will describe this by the constraint

$$
l_{i}(1) \geq \min \left\{l_{i}(0), b_{i}(1)\right\} .
$$

This constraint states that no civil servant can be fired if the current budget is sufficiently large to pay the wage bill. For completeness (3) also states what happens if the period 1 budget of a division is smaller than the wage bill of the set of civil servants who were hired in period 0. We assume that, in this case, the division has to spend all its budget on the wage bill, and nothing on the variable factor of production.

Turn now to the output of the divisions. We assume that

$$
g_{i}(t)=\sqrt{l_{i}(t) z_{i}(t)}
$$

\footnotetext{
${ }^{5}$ Note that, when it comes to actual bureaucracies, the hiring of permanent civil servants is only partially under the full discretion of the division head. We see this as one of the practical counter measures to the time consistency problems we study, but, for identifying the problem, it is useful to abstract from such counter measures.
} 
This parametric (Cobb-Douglas) version of a production function with two essential and complementary factors is seemingly restrictive. However, in order to make the problem tractable and to explicitly solve for the subgame perfect equilibrium of the two-period game, some definite structure is needed. Moreover, this case serves as a benchmark case, and it is clear that a more general description of the production function will not change the main results qualitatively.

We turn now to the objective functions of the government and of the bureaucrats. The government positively values output of the divisions, and negatively values expenditure. But, as the aggregate expenditure of the government is exogenously given here, we can disregard this element in the objective function. The government's objective function can therefore be written as

$$
G=G(0)+G(1) \text { with } G(t)=\ln g_{x}(t)+\ln g_{y}(t) .
$$

The second equality establishes that the objective function has a particular parametric form. Again, this is for the sake of greater transparency.

The government's objective function may represent its constituency's preferences more or less well. As we focus on the incentive problems between the government and the bureaucracy, we disregard any agency problems between the politician and his constituency and consider the objective function (5) to be the measure of efficiency.

Finally we consider the objective functions of the chief bureaucrats of the divisions. The theory of bureaucracy that was briefly discussed in the introduction provides a diversity of possible assumptions about what bureaucrats may care about, but all these assumptions have in common that the bureaucrat cares about his own division, maybe its size or its output etc., and a simple assumption that is plausible and in line with bureaucracy theory more generally is to assume that the chief bureaucrat of divison $i$ cares about the output of his division,

$$
u_{i}=g_{i}(0)+g_{i}(1)
$$

These objective functions are taken as given. From a contract theory perspective, our framework is one in which the set of feasible contracts is very 
limited: the central government can send a budget, and the division head can use it to produce according to his own preferences that cannot be affected further by the central government by contractual arrangements, for reasons outside the scope of this analysis. But fortunately, the preferences of the division head are partially alligned with those of the government.

The more balanced preferences of the government could, for instance, be due to considerations about the preferences of their constituency and the government's concerns about re-election, but for brevity we take (5) simply as given here and do not provide an explicit micro foundation for it. Finally note that the objective functions of the government and the bureaucrat implicitly assume (for simplicity) a discount factor equal to unity.

\section{$3 \quad$ Efficiency}

Before we describe the equilibrium allocation of the bureaucrats' budgets, we characterize the efficient allocation as a benchmark case. For this purpose, we concentrate on the case $B(1) \geq B(0)$.

Proposition 1 For $B(1) \geq B(0)$ the allocation that maximizes the value of the objective function of the government is characterized by $b_{i}(t)=\frac{B(t)}{2}$ and by $l_{i}(t)=z_{i}(t)=\frac{B(t)}{4}$ in both periods.

A formal proof is omitted. The proposition simply states that the efficient solution requires production efficiency in both periods and in all divisions, and this is described by the optimal factor intensity. For the specific production function in (4) in which the factors of production are symmetric, efficiency requires a symmetric treatment of all divisions in all periods, given that the output is evaluated symmetrically in the government's objective function and given that this objective function is concave in these outputs.

Throughout the analysis we consider the case $B(1) \geq B(0)$ and disregard the possibility of squeeze of the total budget. A budget squeeze is interesting as well, but the strategic incentives to produce with too high labor intensity in the public sector can more easily be demonstrated for the cases with $B(1) \geq$ 
$B(0)$, as $B(1)<B(0)$ adds complexity. In the case of a budget squeeze with tenured civil servants, the first-best equilibrium that is characterized in proposition 1 cannot be attained. The labor intensity that is first-best in period 0 , if chosen, induces an inefficiency in period 1: the period 1 budget is too small to finance both a labor choice larger or equal to the period 0 choice and the efficient amount of the variable input that comes together with this labor choice. It will generally require optimally less labor to be employed also in period 0 than would be optimal for the static period 0 problem taken in isolation. Accordingly, the efficiency benchmark becomes more difficult, and the comparison between the efficient outcome and the equilibrium outcome becomes less transparent than for the case in Proposition 1. The analysis of a budget squeeze would, however, reveal that the strategic incentive to over-hire civil servants in an early period is also at work if a squeeze of the overall budget is anticipated.

\section{Equilibrium}

We start the equilibrium analysis by a description of the time structure of decisions. In period 0 , in a STAGE 0 the government decides how to split the available budget $B(t)$ between the divisions. The choice can be described in general by some vector $\mathbf{b}(0) \equiv\left(b_{x}(0), b_{y}(0)\right)$ for which $(1)$ holds. For an analysis of the strategic incentives of the divisions of the bureacracy, we assume that the government splits the budget evenly between the two divisions in period $0, b_{x}(0)=b_{y}(0)=B(0) / 2$ as the starting point, as this is what would happen in in the efficiency benchmark case in Proposition 1. In STAGE 1 the bureaucrats decide on $l_{i}(0)$ and $z_{i}(0)$, subject to the budget constraint (2). Then the period outputs accrue and period 0 ends. In period 1, first, in STAGE 2, the government allocates $B(1)$ to the divisions, and the allocation chosen is described by a vector $\mathbf{b}(1) \equiv\left(b_{x}(1), b_{y}(1)\right)$ for which (1) holds. Then, in STAGE 3 the bureaucrats choose how to spend their budgets on $l_{i}(1)$ and $z_{i}(1)$ subject to the budget constraint (2) and the labor constraint (3). Finally, output accrues and the game ends. 
Proposition 2 Let $B(0)=B(1) \equiv B$, and let $b_{x}(0)=b_{y}(0)=B / 2$. Then

$$
l_{i}(0)=\frac{2 B}{7}, b_{i}(1)=\frac{B}{2} \text { and } l_{i}(1)=\frac{2 B}{7}
$$

are equilibrium values of choices in the subgame perfect equilibrium of the continuation game.

Proof. For a proof first consider STAGE 3 in period 1: the input choices for given $\mathbf{b}(1) \equiv\left(b_{x}(1), b_{y}(1)\right)$. The bureaucrats in each division simply maximize output. The maximized output is

$$
g_{i}^{*}(\mathbf{b}(1), \mathbf{l}(0))=\left\{\begin{array}{clc}
0 & \text { if } & b_{i}(1)<l_{i}(0) \\
\sqrt{l_{i}(0)\left(b_{i}(1)-l_{i}(0)\right)} & \text { if } & b_{i}(1) \in\left[l_{i}(0), 2 l_{i}(0)\right) \\
\frac{b_{i}(t)}{2} & \text { if } & b_{i}(1) \geq 2 l_{i}(0)
\end{array}\right.
$$

This takes (3) into consideration. Note that the equilibrium choice of $i$ 's period-1 labor input is

$$
l_{i}^{*}(\mathbf{b}(1), \mathbf{l}(0))=\left\{\begin{array}{clc}
l_{i}(1)=b_{i}(1) & \text { if } & b_{i}(1)<l_{i}(0) \\
l_{i}(1)=l_{i}(0) & \text { if } & b_{i}(1) \in\left[l_{i}(0), 2 l_{i}(0)\right) \\
l_{i}(1)=b_{i}(1) / 2 & \text { if } & b_{i}(1) \geq 2 l_{i}(0) .
\end{array}\right.
$$

where use is made of the fact that the unconstrained efficient factor intensity is characterized by $l_{i}(1)=z_{i}(1)$.

Turning now to the budget allocation decision in STAGE 2 at the beginning of period 1 , the government chooses $\mathbf{b}(1)$ to maximize

$$
G(1)=\ln g_{x}^{*}(\mathbf{b}(1), \mathbf{l}(0))+\ln g_{y}^{*}(\mathbf{b}(1), \mathbf{l}(0))
$$

subject to (1) for $t=1$, with $g_{i}^{*}$ defined in (8). The government will avoid infinitely negative payoff if possible. We can therefore rule out $b_{i}(1) \leq l_{i}(0)$, unless in both divisions the bureaucrats choose $l_{i}(0)=b_{i}(0)$, in which case, by $B(0)=B(1)$, zero output in at least one division cannot be avoided.

If $l_{i}(0)=b_{i}(0)$ for both $i=x$ and $i=y$, all feasible budget allocation rules yield an infinitely negative payoff for the government, and we assume that the government allocates the budget evenly among the divisions in this 
case, ${ }^{6}$ leading to $g_{i}(0)=g_{i}(1)=0$ for all divisions, and making $l_{i}(0)=b_{i}(0)$ for both $i=x$ and $i=y$ a strictly dominated choice and rules this out as an equilibrium. Turning to $l_{i}(0)<b_{i}(0)$ for at least one $i \in\{x, y\}$, the optimal budget allocation can be found by the first-order conditions of the constrained optimization problem which yield $\frac{1}{\sqrt{l_{i} z_{i}}} \frac{1}{2} \frac{\sqrt{l_{i}}}{\sqrt{z_{i}}}=\mu$, where $\mu$ is the shadow price of public funds. These conditions can be rewritten as

$$
b_{x}(1)-l_{x}^{*}\left(b_{x}(1)\right)=b_{y}(1)-l_{y}^{*}\left(b_{y}(1)\right)
$$

The government allocates the budget such that, taking the period-1 equilibrium input decisions of the divisions into consideration, both divisions use the same amount of the variable factor in the equilibrium of the continuation game: ${ }^{7}$

$$
z_{x}^{*}\left(\mathbf{b}^{*}(1) ; \mathbf{l}(0)\right)=z_{y}^{*}\left(\mathbf{b}^{*}(1) ; \mathbf{l}(0)\right) .
$$

The constraint (1) for $t=1$ together with (12) yields the equilibrium input of the variable factor in the continuation game with an equilibrium choice $\mathbf{b}^{*}(1)$ for a given choice of period-zero labor inputs $\mathbf{l}(0)$ as

$$
z_{x}^{*}\left(\mathbf{b}^{*}(1) ; \mathbf{l}(0)\right)=\left\{\begin{array}{clc}
\frac{B-l_{y}(0)-l_{x}(0)}{2} & \text { if } & l_{i}(0)>\frac{B}{4} \text { for } i=x, y \\
\frac{B-l_{y}(0)}{3} & \text { if } & l_{y}(0)>\frac{B}{4} \text { and } l_{x}(0) \leq \frac{B}{4} \\
\frac{B-l_{x}(0)}{3} & \text { if } & l_{x}(0)>\frac{B}{4} \text { and } l_{y}(0) \leq \frac{B}{4} \\
\frac{B}{4} & \text { if } & l_{i}(0) \leq \frac{B}{4} \text { for } i=x, y
\end{array}\right.
$$

and analogously for $z_{y}^{*}\left(\mathbf{b}^{*}(1) ; \mathbf{l}(0)\right)$.

\footnotetext{
${ }^{6}$ This is not an innocent assumption. While the government is indifferent in this case, the divisions care a lot about the allocation rule chosen. However, for the interior equilibrium which we consider, this assumption is not crucial.

${ }^{7}$ Optimization that takes into consideration the production subgame in period 1 yields the simple rule that the government makes sure that all divisions choose exactly the same amount of $z$ in period 1 here. One should note that this simple result is due to the particular parametric versions of the governmetal objective function and the production functions of divisions. However, while this makes the problem tractable and solvable explicitly, our qualitative results do not hinge on this particular parametric version.
} 
Turn now to the optimal choice of $l_{x}(0)$ at STAGE 1 in period 0 , for a given choice $l_{y}(0)$. With $b_{x}(0)=B / 2$, bureaucrat $x$ 's payoff is

$$
u_{x}=\sqrt{l_{x}(0)\left(\frac{B}{2}-l_{x}(0)\right)}+\sqrt{\max \left\{l_{x}(0), z_{x}^{*}\left(\mathbf{b}^{*}(1) ; \mathbf{l}(0)\right)\right\} \cdot z_{x}^{*}\left(\mathbf{b}^{*}(1) ; \mathbf{l}(0)\right)} .
$$

Suppose $y$ chooses $l_{y}(0)>\frac{B}{4}$. Then the first-order condition for $x$ becomes

$$
\frac{1}{2} \frac{\frac{B}{2}-2 l_{x}(0)}{\sqrt{l_{x}(0)\left(\frac{B}{2}-l_{x}(0)\right)}}+\frac{1}{2} \frac{\frac{B-l_{y}(0)-l_{x}(0)}{2}-\frac{l_{x}(0)}{2}}{\sqrt{l_{x}(0) \frac{\left(B-l_{y}(0)-l_{x}(0)\right)}{2}}}=0 .
$$

Using that $l_{x}=l_{y}$ in the symmetric equilibrium simplifies this expression to $l^{*}(0)=\frac{2}{7} B$. Second -order conditions are fullfilled.

We also need to rule out that $l_{x}=l_{y}<\frac{B}{4}$ constitute an equilibrium. Suppose $l_{y}(0)<\frac{B}{4}$. Then the first derivative of $(14)$ with respect to $l_{x}(0)$ becomes

$$
\begin{aligned}
& \frac{1}{2} \frac{\frac{B}{2}-2 l_{x}(0)}{\sqrt{l_{x}(0)\left(\frac{B}{2}-l_{x}(0)\right)}}+0>0 \quad \text { for } \quad l_{x}(0)<\frac{B}{4} \\
& \frac{1}{2} \frac{\frac{B}{2}-2 l_{x}(0)}{\sqrt{l_{x}(0)\left(\frac{B}{2}-l_{x}(0)\right)}}+\frac{1}{2} \frac{\frac{B-l_{x}(0)}{3}-\frac{l_{x}(0)}{3}}{\sqrt{l_{x}(0) \frac{B-l_{x}(0)}{3}}} \text { for } \quad l_{x}(0)>\frac{B}{4} \text {. }
\end{aligned}
$$

Accordingly, the optimal $l_{x}(0)$ given $l_{y}(0)<\frac{B}{4}$ is at some $l_{x}(0)>\frac{B}{4}$, which rules out a symmetric equilibrium with $l_{x}(0)=l_{y}(0) \leq \frac{B}{4}$.

Proposition 2 has a simple intuition. If the period budgets do not differ very much, a division's chief bureaucrat can induce an increase in his division's next period budget if he commits to using much labor in the current period. This commitment makes additional resources devoted to this division very productive at the margin. To illustrate, if a bureaucrat can commit to spending all the budget $\hat{b}_{i}(t)$ that the government intended to give his division on labor in period $t$, his division will have considerable resources in terms of manpower in that period. It will then be useful to not only pay their wage bill, but also to give these people office space, paper, pencils, computers and other complementary inputs to make them actually productive. This incentive is exploited by the bureaucrat when hiring much labor in an earlier period. Note, however, that the hiring that takes place in a period prior to $t$ can also distort production in that earlier period. Hence, commitment on a large labor force in the division in the future comes at the cost of inefficient 
production in the present. When making this choice, the bureaucrat weighs the two effects against one another.

The framework can be generalized to more than two divisions. However, if the number of divisions gets large enough, this will, for the parametric version considered here, lead to mixed strategy equilibria. Furthermore, as the number of divisions increases, the incentive to strategically over-employ is reduced on average. The reason is that the strategic interaction gets attenuated and the marginal impact on the government's allocation decision in the future is reduced.

We may want to highlight the importance of the constraint (3) for the result in proposition 2. If, for instance, this constraint does not apply, then, in the equilibrium, the chief bureaucrat in each division will simply maximize $g_{i}(1)$ in period 1 and will choose the optimal factor input mix for achieving this. Accordingly, the optimization problems in period 0 and period 1 become fully independent. In particular, a choice of a large $l_{i}(0)$ does not increase this division's period 1 budget, which, in turn, makes it suboptimal to deviate from the efficient input mix in period 0 as well. Summarizing,

Proposition 3 Consider the continuation game if the government allocates $B(0)$ symmetrically among the divisions if there is no tenure, i.e., if the constraint (3) need not hold. Then, the equilibrium is characterized by

$$
l_{i}(0)=\frac{B(0)}{4}, b_{i}(1)=\frac{B(1)}{2} \text { and } l_{i}(1)=\frac{B(1)}{4} .
$$

The outcome of the budget competition depends also on the relative size of the total budget today versus the size of the budget tomorrow. This effect is not directly visible from comparing the outcomes in propositions 1 and 2, as, in proposition 2, it was assumed that the budget size does not change over time. We will now show that the strategic incentive vanishes in a situation with a sufficiently strong budget increase.

Proposition 4 Let $B(1)=k B(0)$ with $k>1$. Consider the continuation game if the government allocates $B(0)$ symmetrically among the divisions. Then, there exists a $k$ such that divisions choose labor input efficiently, i.e.,

$$
l_{i}(0)=\frac{B(0)}{4}, b_{i}(1)=\frac{B(1)}{2} \text { and } l_{i}(1)=\frac{B(1)}{4}
$$


are equilibrium values of choices in the subgame perfect equilibrium of the continuation game.

Proof. For a proof we show that the strategic incentive to overhire has no bite if $k$ is sufficiently high. Note that $l_{i}(0) \leq b_{i}(0)$. Assume that $B(1)>$ $2 B(0)$. If the government chooses $b_{i}(1)=\frac{B(1)}{2}$, the division bureaucrats will choose $z_{i}(1)=l_{i}(1)=\frac{B(1)}{4}$, and this maximizes $G(1)$ for this given period 1 budget. This optimal choice of $l_{i}(1)$ is larger than the maximum $l_{i}(0)$ that was feasible in period 0 , as this maximum was equal to the period 0 budget $\frac{B(0)}{2}$. Therefore, given that the government can always implement the first-best optimum in period 1 irrespective of period 0 labor choices, the bureaucrats will choose the efficient input mix in period 0 as well.

The comparison of the results in propositions 2 and 4 illustrates that growth of the bureacracy is important for the efficiency of the bureaucrats' decisions. Sufficient budget growth eliminates the strategic impact of some production decisions in earlier periods, even if they yield long term commitment to some factor inputs. This result leads to a hypothesis that can be empirically tested. Bureaucracies with tenured civil servants should be moderately labor intensive in periods preceeding large overall budget increases, and should be highly labor intensive if the expected overall governmental budget growth is small or zero in the near future.

\section{Conclusion}

We have developed a new argument that explains the differences in labor intensity between the private and the public sector. While existing theories have either focussed on benevolent governments trying to induce efficiency in some second-best environment or, alternatively, have stressed the political determinants of employment in the public sector, we point at the role of the government's bureaucracy and the dynamic incentives within that system as an important factor. In particular, we have shown how existing tenure regulations interact with bureaucrats' incentives to expand their budget and production within their division. Tenure regulations effectively transform 
labor into a fixed factor which yields commitment power. Bureaucrats of different government divisions who are competing with each other for centrally allocated funds can use this commitment power strategically. After divisions have hired additional labor, these employees have to be remunerated from the funds allocated to that division in future periods. Furthermore, since production is complementary in labor and other inputs, the central government has a strong incentive to allocate more funds to an overstaffed division in the future since the additional funds will be spent on the complementary inputs of production which have a high marginal product. In the resulting equilibrium, the bureaucrats' strategic interaction results in an inefficiently high level of employment. The effect identified will be strongest in times of constant or slowly growing government budgets but will be attenuated by sufficient budget expansions.

\section{References}

Alesina, Alberto, Reza Baqir, and William Easterly, 2000, Redistributive public employment, Journal of Urban Economics, 48(2), 219-241.

Bagnoli, Mark, and Michael McKee, 1991, Controlling the game: political sponsors and bureaus, Journal of Law, Economics and Organization, 7(2), 229-247.

Boycko, Maxim, Andrei Shleifer and Robert W. Vishny, 1996, A theory of privatization, Economic Journal, 106, 309-319.

Carlsen, Fredrik, and Kjetil Haugen, 1994, Markov perfect equilibrium in multi-period games between sponsor and bureau, Public Choice 79, 257-280.

Chan, Kenneth S. and Stuart Mestelman, 1988, Institutions, efficiency and the strategic behavior of sponsors and bureaus, Journal of Public Economics, 37, 91-102.

Crain, W. Mark, and Lisa K. Oakley, 1995, The politics of infrastructure, Journal of Law and Economics, 38, 1-17.

Dewenter, Kathryn L. and Paul H. Malatesta, 2001, State-owned and privately owned firms: an empirical analysis of profitability, leverage, and 
labor intensity, American Economic Review, 91(1), 320-334.

Forni, Lorenzo and Raffaela Giordano, 2003, Employment in the public sector, CESifo working paper No. 1085.

Gelb, A., J.B. Knight and R.H. Sabot, 1991, Public sector employment, rent-seeking and economic growth, Economic Journal, 101, 1186-1199.

Glazer, Amihai, 1989, Politics and the Choice of Durability, American Economic Review, 79(5), 1207-1213.

Gordon, Roger H., 2003, Taxes and privatization, in: Cnossen, Sijbren and Hans-Werner Sinn (eds.), Public finance and public policy in the new century, MIT press, Cambridge (Mass.), 185-211.

Gupta, S., C. Schiller, H. Ma and E.R. Tiongson, 2001, Privatization, labor and social safety nets, Journal of Economic Surveys, 15(5), 647-669.

Haltiwanger, John and Manisha Singh, 1999, Cross-country evidence on public sector retrenchment, World Bank Economic Review, 13(1), 23-66.

Kraan, Dirk-Jan, 1996, Budgetary Decisions, A Public Choice Approach, Cambridge University Press, Cambridge.

Laffont, Jean-Jacques, and Jean Tirole, 1993, A Theory of Incentives in Procurement and Regulation, MIT Press, Cambridge, MA.

La Porta, Rafael, and Florencio Lopez-de-Silanes, 1999, The benefits of privatization: Evidence from Mexico, Quarterly Journal of Economics 114(4), 1193-1242.

Lopez-de-Silanes, Florencio, Andrei Shleifer and Robert W. Vishny, 1997, Privatization in the United States, RAND Journal of Economics, 28(3), 447471.

Megginson, William L., and Jeffry M. Netter, 2001, From state to market: a survey of empirical studies on privatization, Journal of Economic Literature, 39, 321-389.

Moene, Karl O., 1986, Types of bureaucratic interaction, Journal of Public Economics, 29, 333-345.

Niskanen, William, 1971, Bureauracy and representative government, Aldine Publishing Company, Chicago.

Perssson, Torsten, and Lars E.O. Svensson, 1989, Why a stubborn conservative would run a deficit: Policy with time-inconsistent preferences, Quar- 
terly Journal of Economics, 104(2), 325-345.

Poutvaara, Panu, and Andreas Wagener, 2004, Why is the public sector more labor-intensive? A distortionary tax argument, mimeo., University of Copenhagen.

Omran, Mohammed, 2004, The performance of state-owned entreprises and newly privatized firms: Does privatization really matter?, World Development, 32, 6, 1019-1041.

Rodrik, Dani, 2000, What drives employment in developing countries?, Review of Development Economics, 4(3), 229-243. 